\title{
Influence of Dysprosium Distribution on Properties of Sintered and Aged Dy-doped NdFeB Permanent Magnets
}

\author{
Wang Xiaoli ${ }^{1,3}$, Zhao Lina ${ }^{1}$, Ding Kaihong ${ }^{2}$, Cui Shengli ${ }^{2}$, Sun Yongcong $^{2}$, \\ Li Musen ${ }^{1}$
}

${ }^{1}$ Key Laboratory for Liquid-Solid Structural Evolution and Processing of Materials, Ministry of Education, Shandong University, Jinan 250061, China; ${ }^{2}$ Yantai Shougang Magnetic Materials Inc, Yantai 265500, China; ${ }^{3}$ Jiangsu University of Science and Technology, Zhenjiang 212003 , China

\begin{abstract}
Sintered and aged Dy-doped NdFeB magnets were investigated. The magnetic properties, the microstructures and the compositions were characterized by hysteresis loop instrument, thermal field emission scanning electron microscopy (TFESEM) and energy disperse spectroscopy (EDS), respectively. The results indicate that Dy element is mainly distributed in the Nd-rich phase, Nd-Dy oxides and Dy-rich particles located at the grain boundaries of the sintered magnets, in addition to the main crystal phase $\mathrm{Nd}_{2} \mathrm{Fe}_{14} \mathrm{~B}$. The optimized aging process is beneficial to promote a reasonable diffusion and distribution of Dy element. The Dy contents of Nd-riched phases, Nd-Dy oxide, and Dy-riched particle decrease successively in the sintered, the high temperature aged and the optimally two-stage aged Dy-doped NdFeB permanent magnets. The measurements demonstrate that the enhancement of the coercivity of the aged Dy-doped NdFeB Magnet is caused mainly by the Dy element reasonable distribution.
\end{abstract}

Key words: Dy-doped $\mathrm{NdFeB}$ permanent magnet; dysprosium element distribution; microstructure; main crystal phase $\mathrm{Nd}_{2} \mathrm{Fe}_{14} \mathrm{~B}$; grain boundary phase

Dy-doped Nd-Fe-B magnets have enjoyed considerable attention due to their high magnetic properties, good corrosion resistance performance and wide applications ${ }^{[1]}$. With the further development of modern technology, more and more demands require a strong increase of $(\mathrm{Nd}$, Dy)-Fe-B magnets ${ }^{[2,3]}$. However it is unsustainable to keep the application of Dy-doped sintered magnets because of the scarcity of Dy. Therefore, some microstructure control to increase the coercivity with a less fraction of Dy $(<0.1 \mathrm{Nd})$ or Dy-free is necessary. For this purpose, it is essential to investigate the microstructure of the currently used $(\mathrm{Nd}$, Dy)-Fe-B sintered magnets. It is generally recognized that Dy element is usually doped into the $\mathrm{Nd}-\mathrm{Fe}-\mathrm{B}$ magnets to improve the coercivity since the anisotropy field of $\mathrm{Dy}_{2} \mathrm{Fe}_{14} \mathrm{~B}$ $\left(H_{\mathrm{a}}=15.0 \mathrm{~T}\right)$ is much higher than that of $\mathrm{Nd}_{2} \mathrm{Fe}_{14} \mathrm{~B}\left(H_{\mathrm{a}}=7.6 \mathrm{~T}\right)^{[4]}$.
In fact, the microstructure of the grain boundary phase has a strong influence on the coercivity, because the magnetic coupling of main phase grains influences the coercivity of nucleation-type magnets ${ }^{[5,6]}$. The work was carried out in an attempt to achieve the optimum microstructure, which involved confining the Dy distribution to the grain boundary regions. In order to use Dy more efficiently, the grain boundary diffusion process (GBDP) was introduced to sintered Nd-Fe-B magnets by Park et $\mathrm{al}^{[7]}$. Several investigations indicated that improved magnetic properties of sintered magnets can be achieved by $\mathrm{DyF}_{3}$ for the $\mathrm{GBDP}^{[8-11]}$. An attempt to control the distribution of Dy in $\mathrm{Nd}_{2} \mathrm{Fe}_{14} \mathrm{~B}$ was made by extending post-sintering time ${ }^{[12]}$. It was reported that the grain size increased with the increase of $\mathrm{Dy}_{3} \mathrm{Co}$, and some grains of $\Phi$ phase with dimensions up to $50 \mu \mathrm{m}$ were

\footnotetext{
Received date: January 30, 2015

Foundation item: National Major Special Project for the Rare Earth and Rare Metallic Materials (2012-1743)

Corresponding author: Li Musen, Ph. D., Professor, Key Laboratory for Liquid-Solid Structural Evolution and Processing of Materials, Ministry of Education, Shandong University, Jinan 250061, P. R. China, Tel: 0086-531-88395693, E-mail: msli@ @du.edu.cn

Copyright (C) 2016, Northwest Institute for Nonferrous Metal Research. Published by Elsevier BV. All rights reserved.
} 
observed. WDX (wave length dispersion X-ray) analysis revealed that Dy could not be detected in the central region of the grains, while a nearly constant Dy-concentration was found in the border region. L. Y. Gao et al. ${ }^{[13]}$ studied $\mathrm{Nd}_{16} \mathrm{Fe}_{76} \mathrm{~B}_{8}$ with $\mathrm{DyH}_{3}$ addition at different sintering temperatures. The situation of Dy penetrating to the hard matrix phase was observed in detail, and an evolution mode of the relevant sintering process was proposed. W. F. Li et al. ${ }^{[14]}$ found Dy atoms were not uniformly distributed in the microstructure but some Dy oxides were presented at the basically aged temperature of $500 \sim 600{ }^{\circ} \mathrm{C}$ for $3 \sim 5 \mathrm{~h}$.

To develop high-coercivity sintered magnets with smaller additions of Dy, a good knowledge of the distribution of Dy in sintered (Nd, Dy)-Fe-B magnets is necessary. Hence, the aim of the present work is to investigate Dy element distribution in the ( $\mathrm{Nd}, \mathrm{Dy})-\mathrm{Fe}-\mathrm{B}$ magnet alloys during the optimized aging process.

\section{Experiment}

(Nd, Dy)-Fe-B magnets of the commercial magnetic alloys with the serial number of N35TH have been employed. The samples were prepared by the standard powder metallurgy method using multiple alloy powders doped Dy-Fe alloy powders. After magnetic field alignment and pressing, green compacts were sintered at $1050{ }^{\circ} \mathrm{C}$ for $2 \mathrm{~h}$. After the sintering process, two stages of aging heat treatments were adopted. In order to find the best temperature, several aging treatments were applied on the sintered magnets by an electric tube furnace in $10^{-3} \mathrm{~Pa}$ vacuum: firstly high-temperature aging between $600{ }^{\circ} \mathrm{C}$ and $1050{ }^{\circ} \mathrm{C}$ with an interval of $50{ }^{\circ} \mathrm{C}$ and holding for $2 \mathrm{~h}$; and then low-temperature aging between 430 ${ }^{\circ} \mathrm{C}$ and $560{ }^{\circ} \mathrm{C}$ with an interval of $10^{\circ} \mathrm{C}$ and holding for $2 \mathrm{~h}$. Then the optimum post-sintering annealing was made at $800 \sim 900{ }^{\circ} \mathrm{C}$ for $2 \mathrm{~h}$ (namely high temperature aged process), followed by aging at $430 \sim 500{ }^{\circ} \mathrm{C}$ for $2 \mathrm{~h}$ and quenching to room temperature.

Magnetic properties of the magnets were measured at room temperature with the NIM-2000 magnetic properties instrument. The microstructure, the fractures and the composition were examined by a field emission scanning electron microscope (FESEM) (SU-70 model made in Japan) equipped with an energy dispersive spectrometer (EDS). The element distribution mapping was examined by an electron probe micro analyzer (EPMA).

\section{Results and Discussion}

\subsection{Magnetic properties}

Fig. 1 shows the demagnetization curves of the sintered and post-sintered-aged ( $\mathrm{Nd}, \mathrm{Dy})-\mathrm{Fe}-\mathrm{B}$ magnets. The main magnetic parameters of the test specimen are listed in Table 1. It should be noted that the large increase in coercivity is obtained in the post-sintering-aging process in comparison with the as-sintered magnets. The coercivity of the sintered

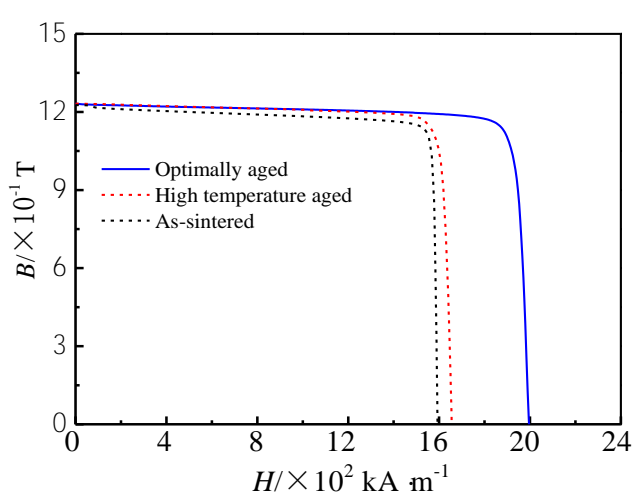

Fig.1 Demagnetization curves of the (Nd, Dy)-Fe-B magnets

Table 1 Comparison of magnetic properties of as-sintered, high temperature aged and optimally aged Dy-doped magnets

\begin{tabular}{cccc}
\hline Sample & As-sintered & $\begin{array}{c}\text { High temperature } \\
\text { aged }\end{array}$ & $\begin{array}{c}\text { Optimally } \\
\text { aged }\end{array}$ \\
\hline$B_{\mathrm{r}} / \mathrm{T}$ & 1.2263 & 1.2321 & 1.2318 \\
$H_{\mathrm{cj}} / \mathrm{kA} \cdot \mathrm{m}^{-1}$ & 1592.96 & 1655.92 & 1995.92 \\
$\left(H_{\mathrm{k}} / H_{\mathrm{cj}}\right)$ & 0.975 & 0.954 & 0.950 \\
$(B H)_{\max } / \mathrm{kA} \cdot \mathrm{m}^{-3}$ & 288.256 & 297.888 & 297.216 \\
\hline
\end{tabular}

magnets is $1592.96 \mathrm{kA} / \mathrm{m}$. Particularly, the coercivity increases drastically from 1655.92 to $1995.92 \mathrm{kA} / \mathrm{m}$ by the optimally aged process when aged at high temperature. The $H_{\text {cj }}$ is increased obviously by $25.3 \%$.

\subsection{Microstructural analysis}

BSE (back scattered electron) images of the as-sintered, high temperature aged and optimally aged magnets are presented in Fig. 2a to 2c, respectively. Five phases can be identified in the magnets: the matrix phase (marked as A), block-like $(\mathrm{Nd}, \mathrm{Dy})$-rich phase at the triple junctions region (marked as B), the Nd-Dy oxide distributed among the main phase grains (marked as C), a Dy relatively rich phase (marked as D) and grain boundary phase (marked as E).

From Fig.2a to $2 \mathrm{c}$, the microstructure variations of the Dy-doped Nd-Fe-B magnets can be detected. Fig.2a shows that the main crystal phase (the gray region marked by arrow A) boundaries of the sintered sample are not clear and the distribution of the $(\mathrm{Nd}$, Dy)-rich phase (the white region marked by arrow B) is not continuous and uniform. Also, more (Nd,Dy)-rich phase appears mainly and is gathered in the triple junctions of the main crystal phase $\mathrm{Nd}_{2} \mathrm{Fe}_{14} \mathrm{~B}$. In Fig.2b, the (Nd, Dy)-rich phase emerges along the grain boundary when aged at high temperature, the aggregation of the $(\mathrm{Nd}, \mathrm{Dy})$-rich phase is significantly reduced, but the grain boundary is still unclear, indicating the existence of exchange coupling between the main phase grains ${ }^{[8]}$. This is the reason 

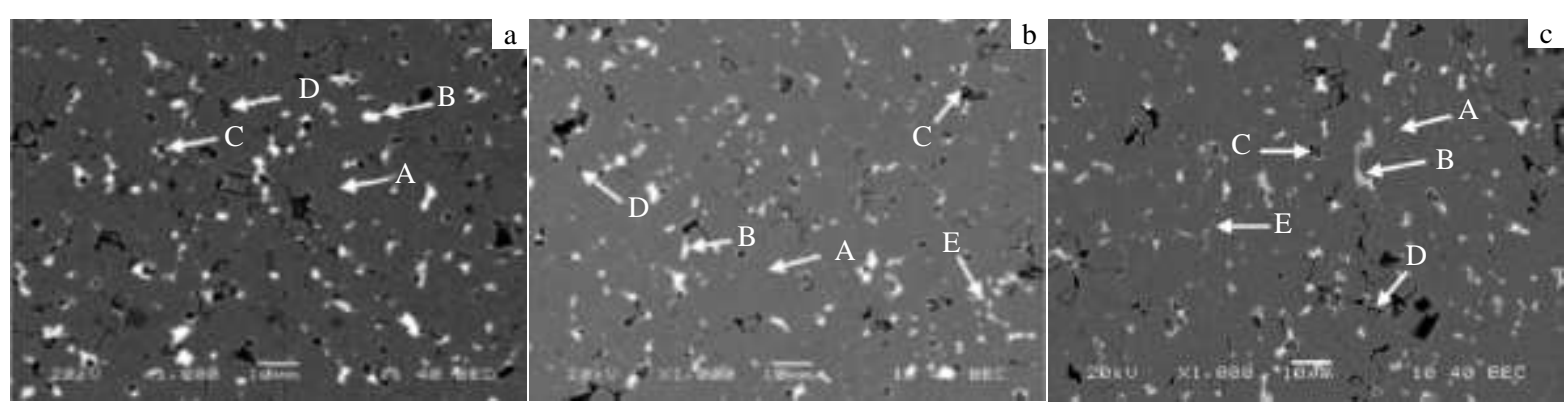

Fig.2 BSE images of as-sintered (a), high temperature aged (b) and optimal aged (c) (Nd, Dy)-Fe-B magnets; (Nd, Dy)-Fe-B main phase, (Nd, Dy)-rich phase, Nd-Dy oxide, Dy-rich phase and grain boundary phase are marked by arrow A, B, C, D and E, respectively

for the low coercivity of as-sintered and high temperature aged magnets. Moreover, mass particles (marked by arrow C) distributed among the main phase grains could be found in the magnet in Fig.2. The EDS analysis indicates that these particles are Nd-Dy oxide compound. Dy-rich particles (marked by arrow D) are also found among main phase grains. After the optimally aging process, the grain boundaries (marked by arrow E) become clearer, as shown in Fig.2c.

In order to study the distribution of $\mathrm{O}, \mathrm{Dy}, \mathrm{Nd}$, and $\mathrm{Fe}$ in the optimally aged NdDy-Fe-B magnets, the elemental mapping was taken by EPMA. Fig.3a shows the BSE-SEM image (backscattered electron-scattered section microscope image) and Fig.3b shows the elemental distribution mapping of Dy, Nd, Fe and O. It can been seen that the scanned region

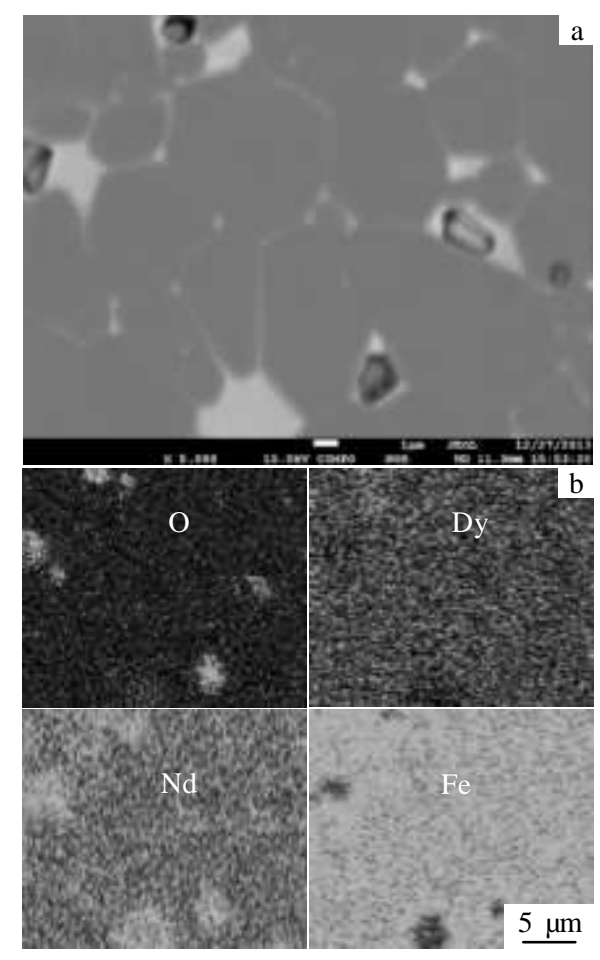

Fig.3 BSE-SEM image showing (Nd, Dy)-rich and $\mathrm{Nd}_{2} \mathrm{Fe}_{14} \mathrm{~B}$ phases of optimally aged (Nd, Dy)-Fe-B magnets (a), and EPMA mapping of $\mathrm{O}$, Dy, $\mathrm{Nd}$ and $\mathrm{Fe}(\mathrm{b})$ including a Nd-rich phase in which $\mathrm{O}$ content is low and a Nd-rich phase where $\mathrm{O}$ content is high. The oxygen is enriched in some grains located on $\mathrm{Nd}_{2} \mathrm{Fe}_{14} \mathrm{~B}$ matrix phase. The level of $\mathrm{Fe}$ is low in the Nd-rich phase. The distribution of Dy is uniform in the $\mathrm{Nd}_{2} \mathrm{Fe}_{14} \mathrm{~B}$ grains and it means that the high-anisotropy $(\mathrm{Nd}$, Dy) ${ }_{2} \mathrm{Fe}_{14} \mathrm{~B}$ phase has been formed by substituting Dy for part of $\mathrm{Nd}$ in the $\mathrm{Nd}_{2} \mathrm{Fe}_{14} \mathrm{~B}$ phase. But there are still some Dy-rich points in the magnets and a Dy-poor region exists in a Nd-rich phase where $\mathrm{O}$ content is low, and it suggests that Dy has a stronger affinity with oxygen compared to $\mathrm{Nd}$, and thus $\mathrm{Dy}$ forms an oxide preferentially leaving $\mathrm{Nd}$ as a metallic phase. The results agree with the suggestion of W. F. Li et al ${ }^{[14]}$.

Fig. 4 shows the composition variation across the region
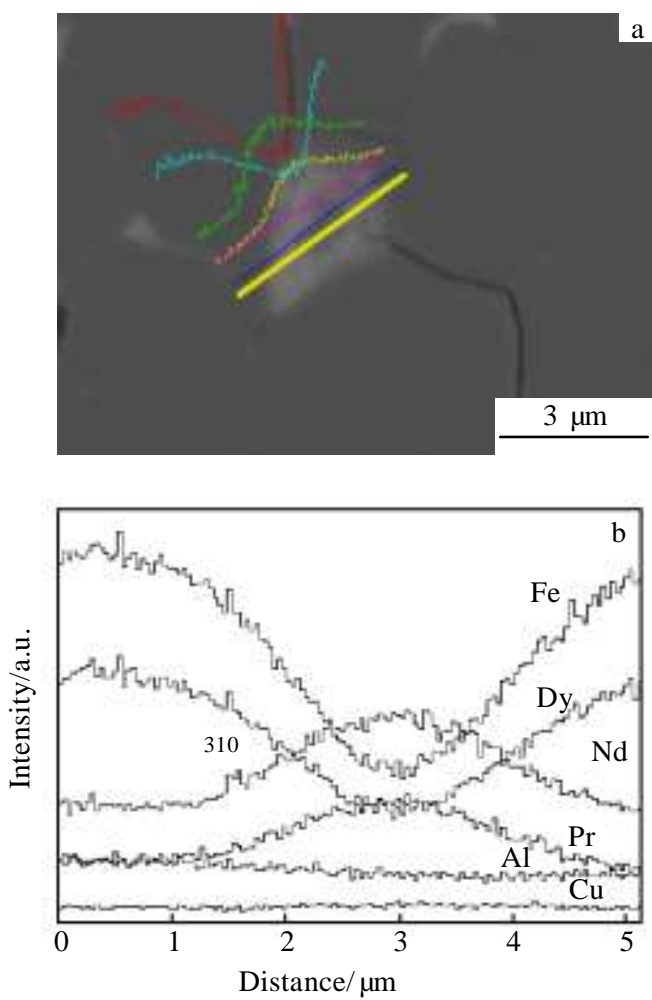

Fig.4 Enlarged BSE-SEM image showing the Nd-rich regions and the $\mathrm{Nd}_{2} \mathrm{Fe}_{14} \mathrm{~B}$ matrix phase (a); EDS line scan across the Nd-rich region marked in Fig.4a (b) 
from the $\mathrm{Nd}_{2} \mathrm{Fe}_{14} \mathrm{~B}$ matrix phase to Nd-rich region. It suggests that the distribution of the Dy element in the optimally aged (Nd,Dy)-Fe-B magnet exhibits similar distribution as $\mathrm{Fe}$, indicating that most Dy exists in the $\mathrm{Nd}_{2} \mathrm{Fe}_{14} \mathrm{~B}$ matrix phase grains and grain boundary phase, but not in the Nd-rich phase.

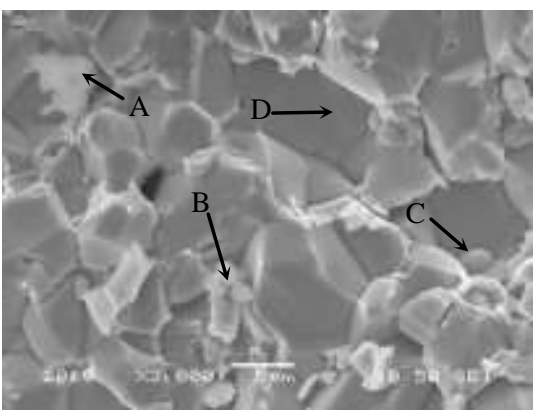

Dy-doped NdFeB permanent magnet has excellent magnetism because the Dy element distribution is not only in the main crystal phase $\mathrm{Nd}_{2} \mathrm{Fe}_{14} \mathrm{~B}$, but also in the grain boundary phases. In order to study the distribution of Dy during the optimally aging process, fracture morphology and EDS analyses were carried out. From Figs.5 7 and Table 2, it

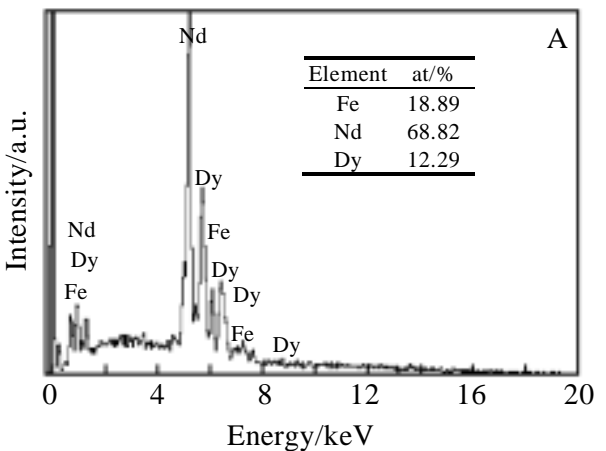

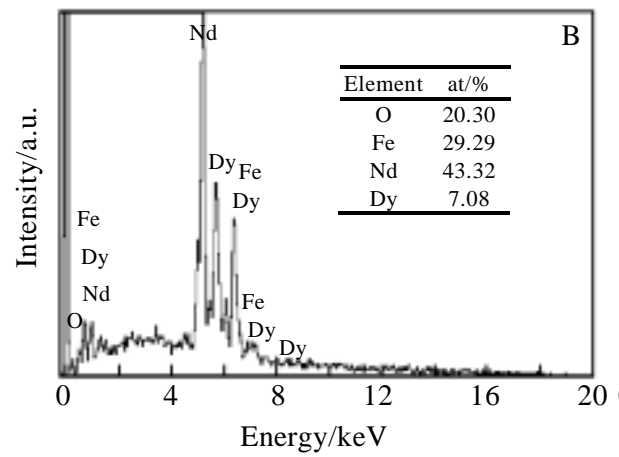
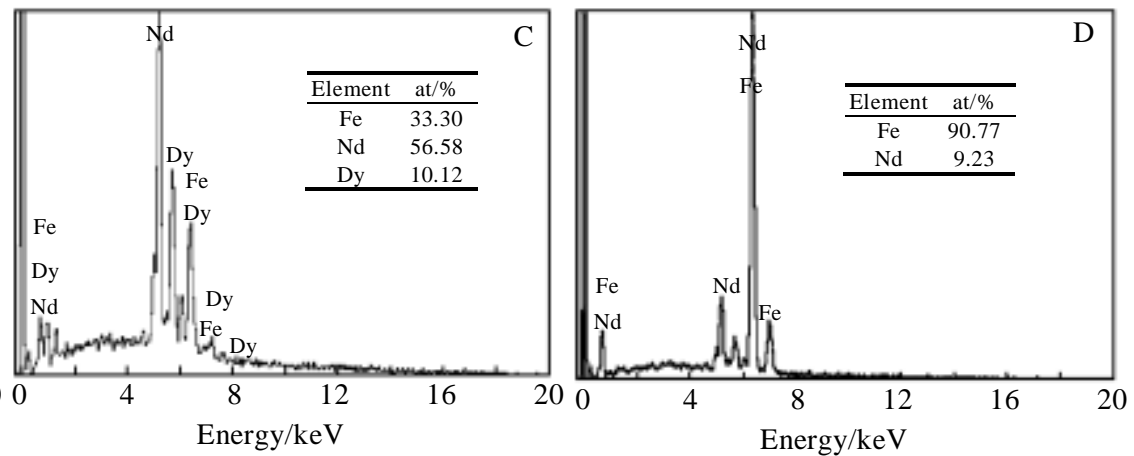

Fig.5 Fracture morphology and EDS spectra of the as sintered (Nd, Dy)-Fe-B magnets; (Nd, Dy)-rich phase, Nd-Dy oxide, Dy-rich phase and the matrix phase are marked A, B, C, and D respectively
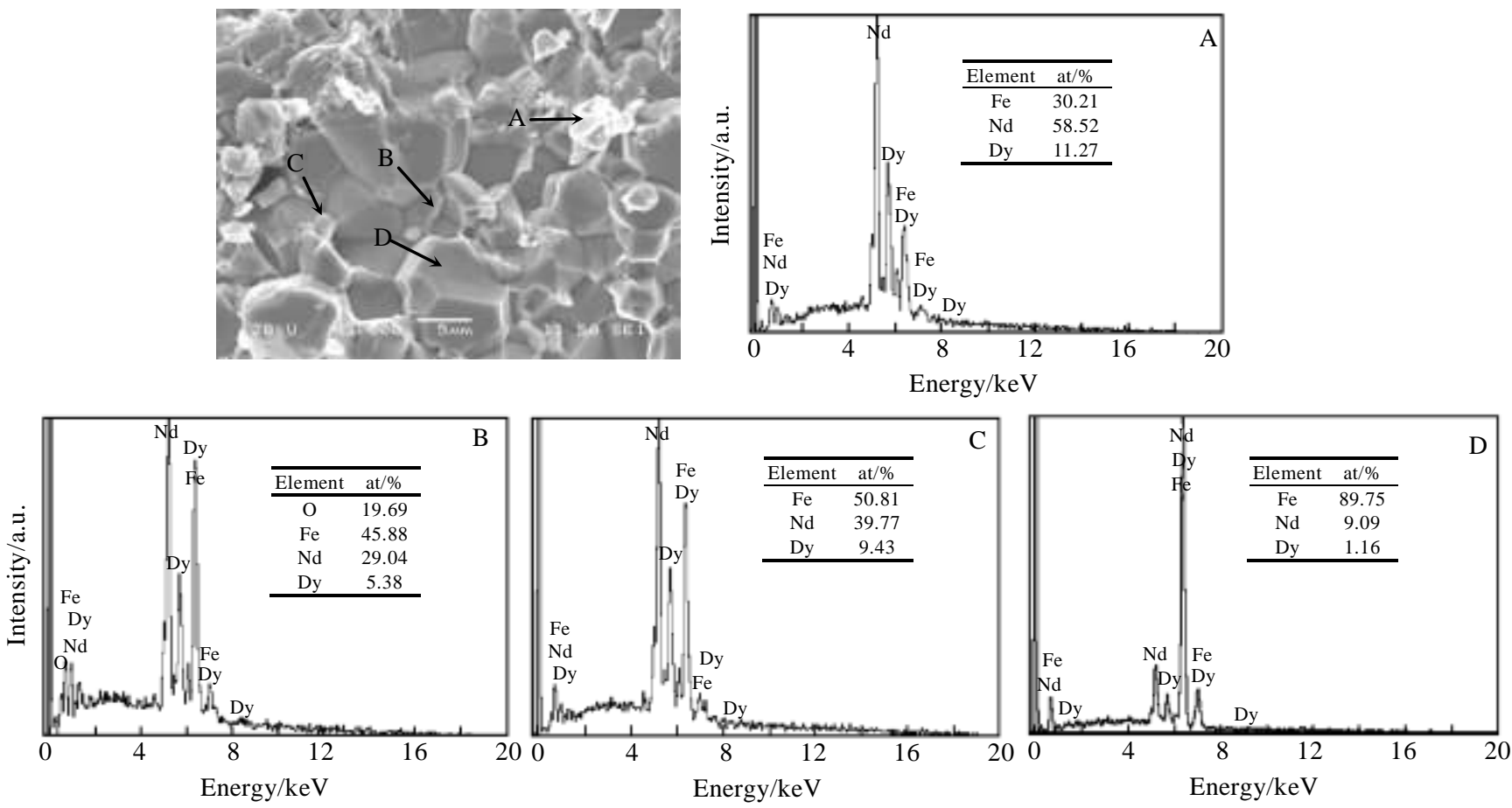

Fig.6 Fracture morphology and EDS spectra of high temperature aged (Nd, Dy)-Fe-B magnets; (Nd, Dy)-rich phase, Nd-Dy oxide, Dy-rich phase and the matrix phase are marked $\mathrm{A}, \mathrm{B}, \mathrm{C}$, and $\mathrm{D}$ respectively 

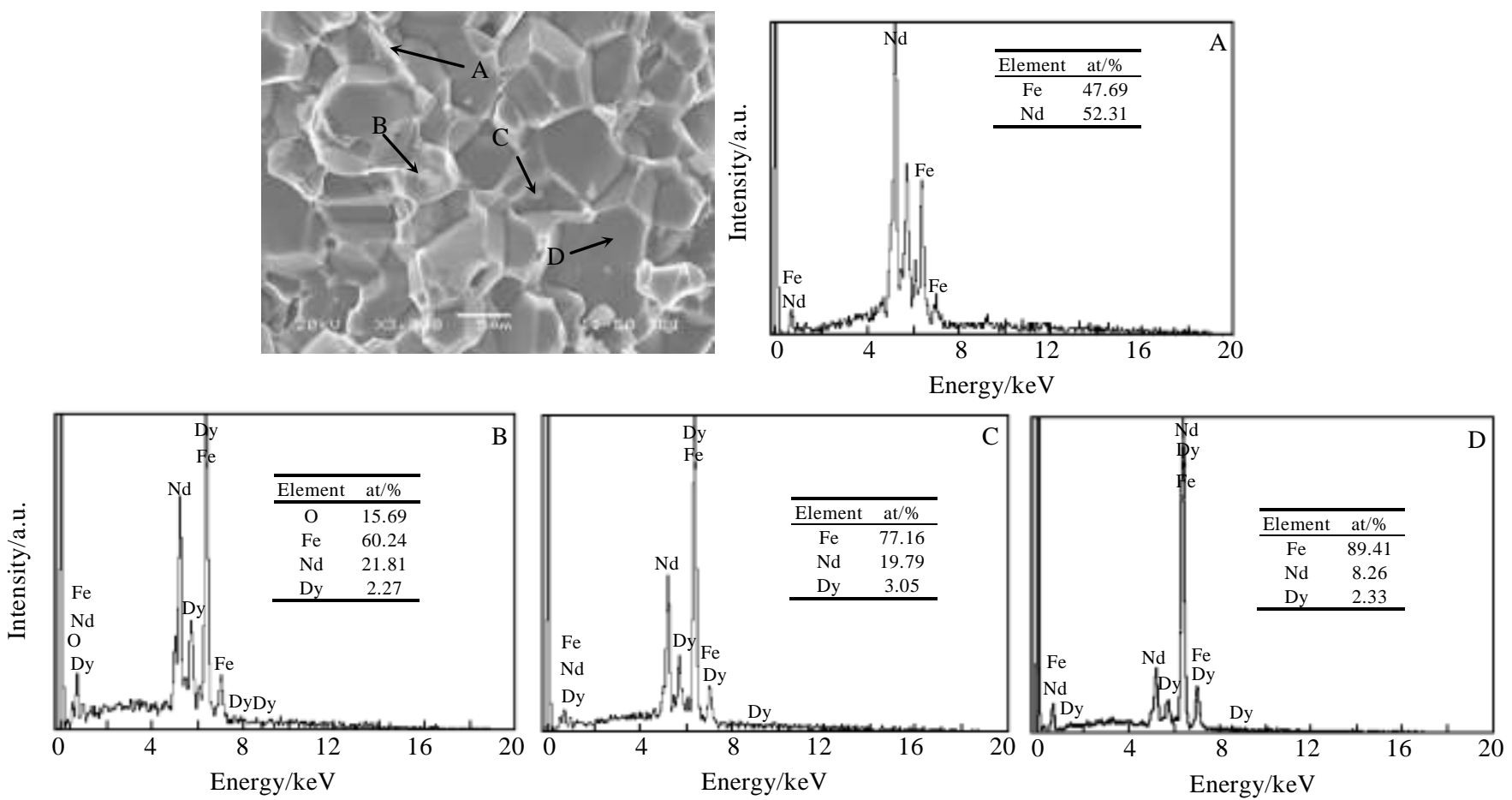

Fig.7 Fracture morphology and EDS spectra of the optimally aged (Nd, Dy)-Fe-B magnets; (Nd, Dy)-rich phase, Nd-Dy oxide, Dy-rich phase and the matrix phase are marked A, B, C, and D respectively

Table 2 Composition of the high temperature aged and the optimally aged NdDy-Fe-B magnets by EDS (at\%)

\begin{tabular}{|c|c|c|c|c|c|}
\hline & \multirow{2}{*}{ Position } & \multicolumn{4}{|c|}{ Composition } \\
\hline & & $\mathrm{Fe}$ & $\mathrm{Nd}$ & Dy & $\mathrm{O}$ \\
\hline $\mathrm{a}$ & \multirow{3}{*}{$\begin{array}{c}\text { A } \\
\text { Nd-rich phase }\end{array}$} & 18.89 & 68.82 & 12.29 & - \\
\hline $\mathrm{b}$ & & 30.21 & 58.52 & 11.27 & - \\
\hline $\mathrm{c}$ & & 47.69 & 52.31 & - & - \\
\hline $\mathrm{a}$ & \multirow{3}{*}{$\begin{array}{c}\text { B } \\
\text { Nd-Dy oxide }\end{array}$} & 29.29 & 43.32 & 7.08 & 20.30 \\
\hline $\mathrm{b}$ & & 45.88 & 29.04 & 5.38 & 19.69 \\
\hline $\mathrm{c}$ & & 60.24 & 21.81 & 2.27 & 15.69 \\
\hline $\mathrm{a}$ & \multirow{3}{*}{$\begin{array}{c}\mathrm{C} \\
\text { Dy-rich particles }\end{array}$} & 33.30 & 56.58 & 10.12 & - \\
\hline $\mathrm{b}$ & & 50.81 & 39.77 & 9.43 & - \\
\hline $\mathrm{c}$ & & 77.16 & 19.79 & 3.05 & - \\
\hline $\mathrm{a}$ & \multirow{3}{*}{$\frac{\mathrm{D}}{\text { the matrix phase }}$} & 90.77 & 9.23 & - & - \\
\hline $\mathrm{b}$ & & 89.75 & 9.09 & 1.16 & - \\
\hline c & & 89.41 & 8.26 & 2.33 & - \\
\hline
\end{tabular}

can be seen that Dy element is mainly distributed in the $(\mathrm{Nd}$, Dy)-rich phase (at the triple junctions of main phase grains), Nd-Dy oxide (between the main phase grains), Dy-rich particles like the cobblestone shape (located in the main phase grains) and the matrix phase $\mathrm{Nd}_{2} \mathrm{Fe}_{14} \mathrm{~B}$. Among the sintered, the high temperature aged and the optimally two-stage-aged Dy-doped NdFeB permanent magnets, it is showen that the Dy contents of the different phases change obviously, and they are the highest in the Nd-riched phases, Nd-Dy oxide, and Dy-riched particles at the grain boundary of the sintered Dy-doped $\mathrm{NdFeB}$ permanent magnet, but they are lower in those of the high temperature aged one, and the lowest or disappear in the those of the optimally two-stage aged one. Meanwhile, the Dy content in the matrix phase increases gradually.

As shown in Figs.5 7 and Table 2, after being optimally aged, Dy content of the Nd-Dy oxide particles decreases from $7.08 \mathrm{at} \%$ in the sintered magnets to $2.27 \mathrm{at} \%$ in the optimally aged magnets, while the oxygen content decreases from 20.30at\% to 15.69 at\%. It means that Dy and $O$ have diffused into the $(\mathrm{Nd}$, Dy)-rich phase. Meanwhile, the disappearance of Dy element distributed in ( $\mathrm{Nd}$, Dy)-rich phase means that this part of Dy completely diffuses into the grain boundary region and leads to the increase of the magnetic anisotropy at the grain surface to stabilize the state of aligned domains. The oxygen may dissolve and offer a 
lubricant effect when the layer of $(\mathrm{Nd}, \mathrm{Dy})$-rich phase is formed on the grain boundary ${ }^{[15]}$. Dy content of the Dy-rich particles located at the main grains decreases from $10.12 \mathrm{at} \%$ to $3.05 \mathrm{at} \%$ and $\mathrm{Nd}$ content decreases from $56.58 \mathrm{at} \%$ to 19.79 at\%. Dy content of the matrix phase increases from 0 to $2.33 \mathrm{at} \%$. It indicates that Dy atoms may diffuse into $\mathrm{Nd}_{2} \mathrm{Fe}_{14} \mathrm{~B}$ matrix and exist as $(\mathrm{Nd}, \mathrm{Dy})_{2} \mathrm{Fe}_{14} \mathrm{~B}$ phase which has much larger $\mathrm{Ha}$ than that of the $\mathrm{Nd}_{2} \mathrm{Fe}_{14} \mathrm{~B}$ phase, resulting in that $H_{\mathrm{ci}}$ of the (Nd, Dy)-Fe-B magnet is Table 2.

\section{Conclusions}

1) Dy element (except for the matrix phase) is mainly distributed in the Nd-rich phase, Nd-Dy oxide and Dy-rich particles like the cobblestone shape in the sintered magnets.

2) The optimized aging process promotes the diffusion of Dy element.

3) Based on the comparison among the sintered, the high temperature aged and the optimal two-stage aged Dy-doped $\mathrm{NdFeB}$ permanent magnets, the Dy contents of the different phases change obviously and they are the highest in the Nd-riched phases, Nd-Dy oxide, and Dy-riched particle at the grain boundary of the sintered Dy-doped NdFeB permanent magnet, but they are lower in those of the high temperature aged one, and they are the lowest or disappear in those of the optimally two-stage aged one.

4) Dy-doped $\mathrm{NdFeB}$ permanent magnet have excellent magnetism due to Dy element reasonable distribution not only in the main crystal phase $\mathrm{Nd}_{2} \mathrm{Fe}_{14} \mathrm{~B}$, but also in the grain boundary phases.
1 Luo Y. Rare Earth Information[J], 2009, 5: 6

2 Gutfleisch O, Willard M A, Bruck E et al. Adv Mater[J], 2011, 23: 821

3 Sugimoto S. Phys D: Appl Phys[J], 2011, 44: 064001

4 Kronmüller H, Durst K D, Sagawa M. J Magn Magn Mater [J], 1988, 74: 291

5 Mo W, Zhang L, Liu Q Z et al. Scripta Materialia[J], 2008, 59: 179

6 Li W F, Ohkubo T, Hono K. Acta Materialia[J], 2009, 57: 1337

7 Park K, Hiraga K, Sagawa M. REPMP Proceedings of 16th International Work-shop on RE Magnets and their Applications[C]. Sendai, Japan: The Japan Institute of Metals, 2000: 257

8 Nakamura $\mathrm{H}$, Hirota $\mathrm{K}$, Shimao $\mathrm{M}$ et al. IEEE Trans Magn[J], 2005, 41: 3844

9 Hirota K, Nakamura H, Minowa T. IEEE Trans Magn[J], 2006, 42: 2909

10 Komuro M, Satsu Y, Suzuki H. IEEE Trans Magn[J], 2010, 46: 3831

11 Xu F, Wang J, Dong X P et al. J Alloy Compd[J], 2011, 509: 7909

12 Velicescu M, Schrey P, Rodewald W. IEEE Trans Magn[J], 1995, 31: 3623

13 Gao L Y, Mcguiness P J, Farr J P G. J Alloy Compd[J], 2010, 491: 20

14 Li W F, Sepehri-Amin H, Ohkubo T et al. Acta Materialia[J], 2011, 59: 3061

15 Fidler J. IEEE Trans Magn[J] 1985, 21: 1955

\title{
References
}

\section{镝的分布对烧结和时效含镝钕铁硼永磁合金性能的影响}

\author{
王晓丽 ${ }^{1,3}$, 赵利娜 ${ }^{1}$, 丁开鸿 ${ }^{2}$, 崔胜利 ${ }^{2}$, 孙永聪 ${ }^{2}$, 李木森 ${ }^{1}$ \\ (1. 山东大学 材料液固结构演变与加工教育部重点实验室, 山东 济南 250061)
}

(2. 烟台首钢磁性材料有限公司, 山东 烟台 265500)

(3. 江苏科技大学, 江苏 镇江 212003)

\begin{abstract}
摘 要: 研究了烧结和时效含镝钕铁硼磁体。通过对不同状态磁体的磁滞曲线, 场发射扫描电镜以及能谱对磁体的磁性能, 微结构以及 成分进行了分析。结果表明, 除了主晶相外, 镝元素主要分布在富钕相, 钕镝氧化物和位于晶界的富镝颗粒中。优化时效过程促进了镝 在磁体中合理的扩散以及分布, 镝在烧结磁体, 高温时效磁体以及优化时效磁体中富钕相, 钕镝氧化物以及含镝颗粒中的含量减少, 证 明了优化时效后，镝元素在磁体中的合理分布，导致了含镝钕铁硼永磁合金矫顽力的提高。
\end{abstract}

关键词：含镝钕铁嗍永磁合金; 镝的分布; 微结构; 主晶相 $\mathrm{Nd}_{2} \mathrm{Fe}_{14} \mathrm{~B}$; 晶界相

作者简介: 王晓丽, 女, 1975 年生, 博士生, 山东大学材料液固结构演变与加工教育部重点实验室, 山东济南 250061 , 电话: 0531-88395693,E-mail: happysmile555@yeah.net 